\title{
As bonecas do amor no Japão: (outros) corpos que importam em contextos de crise
}

\author{
Love dolls in Japan: (other) bodies that matter in contexts of crisis
}

\section{Las muñecas de amor en Japón: (otros) cuerpos que importan en contextos de crisis}

\section{Christine Greiner}

Professora livre-docente da PUC-SP, onde ensina no curso de Artes do Corpo e no Programa de Estudos Pós-Graduados em Comunicação e Semiótica. É autora de diversos livros e artigos sobre corpo, cultura japonesa, filosofia política e arte. Atualmente, é bolsista de produtividade em pesquisa 2 (PQ2) pelo $\mathrm{CNPq}$

\section{Beatriz Yumi Aoki}

Doutoranda e Mestre em Comunicação e Semiótica pela PUC-SP, bolsista CAPES PROSUP (taxa) e PDSE (Programa de Doutorado Sanduíche no Exterior) na Universidade de Tsukuba, no Japão. Bacharel em Comunicação Social (Publicidade e Propaganda) pela ESPM-SP.

\section{RESUMO}

No Japão, as bonecas sexuais são chamadas love dolls ou bonecas do amor. Essa denominação revela uma multiplicidade de relacionamentos entre elas e os seus usuários, que vai muito além da prática sexual, apresentando modos de lidar com a solidão e as novas possibilidades para compreender os vínculos afetivos e seus processos comunicacionais. Há relatos de bonecas companheiras de viagens e de momentos de lazer, modelos para fotografias e maquiagens e, até mesmo, aquelas que são objetos de amor. 0 mercado cresceu tanto no Japão que a empresa Ningen Love Doll passou a organizar funerais específicos para bonecas, a exemplo do que já foi realizado com pets robôs. 0 objetivo deste artigo é demonstrar que a pesquisa sobre os afetos dos japoneses, por seres inorgânicos (bonecas, robôs, hologramas etc.), alinha-se com discussões em torno das novas materialidades e das questões de gênero, suscitando reflexões fundamentais para lidar com situações de crise que fazem repensar epistemologias da comunicação e do corpo. Em termos metodológicos, realizamos uma pesquisa de campo no Japão entre 2019 e 2020 e uma análise bibliográfica que reúne autores como Giard (2016), Esposito (2016), Perniola (2005), Braidotti (2013) e entre outros.

PALAVRAS-CHAVE: Bonecas sexuais; Gênero; Japão; Materialidades.

\section{ABSTRACT}

In Japan, sex dolls are known as love dolls. This denomination reveals a multiplicity of relationships between the dolls and their users, which go far beyond sexual practice and present ways of dealing with loneliness and new possibilities of understanding affective bonds and their communication processes. There are reports of dolls used as travel and leisure companions, models for photographs and makeup, and even as objects of love. The market grew so much in Japan that the company Ningen Love Doll started offering special funerals for 
dolls, as already made for robot pets. The aim of this article is to demonstrate that research on Japanese affections for inorganic beings (such as dolls, robots, holograms, etc.) aligns with discussions around new materialities and gender, raising fundamental reflections in order to deal with crisis situations that rethink epistemologies of communication and the body. In methodological terms, we conducted a field research in Japan between 2019 and 2020; and a bibliographic analysis that brings together authors such as Giard (2016), Esposito (2016), Perniola (2005), Braidotti (2013), among others.

KEYWORDS: Sex dolls; Gender; Japan; Materialities.

\section{RESUMEN}

En Japón, las muñecas sexuales se llaman love dolls o muñecas de amor. Esta denominación revela una multiplicidad de relaciones entre ellos y sus usuarios, que va mucho más allá de la práctica sexual, presentando formas de lidiar con la soledad y nuevas posibilidades para entender los lazos afectivos y sus procesos de comunicación. Hay informes de muñecas usadas como compañía de viaje y tiempo libre, modelos para fotografías y maquillaje, e incluso aquellos que son objetos de amor. El mercado creció tanto en Japón que la compañía Ningen Love Doll comenzó a organizar funerales específicos para muñecas, como ya era hecho con las mascotas robot. El objetivo de este artículo es demostrar que la investigación sobre el afecto japonés por los seres inorgánicos (muñecas, robots, hologramas, etc.) se alinea con las discusiones en torno a nuevas materialidades y cuestiones de género, planteando reflexiones fundamentales para hacer frente a situaciones de crisis que replantan las epistemologías de la comunicación y el cuerpo. En términos metodológicos, realizamos una investigación de campo en Japón entre 2019 y 2020; y un análisis bibliográfico que reúne a autores como Giard (2016), Esposito (2016), Perniola (2005), Braidotti (2013), entre otros.

PALABRAS CLAVE: Muñecas sexuales; Género; Japón; Materialidades.

Submetido em 25 de Julho de 2020

Aceito em 11 de Abril de 2021

\section{Introdução}

O tema da sexualidade e dos afetos no Japão parece, sob muitas perspectivas, bastante exótico para os Ocidentais. Bonecas e outros objetos de estimação fazem parte do dia a dia de pessoas no mundo todo. No entanto, em diversos sentidos, o apego dos japoneses pelos seres inorgânicos chega a situações extremas, como no caso dos matrimônios transdimensionais entre pessoas e seus personagens favoritos de desenhos animados ou de jogos de videogame ${ }^{1}$

\footnotetext{
${ }^{1}$ CNN. Tokyo man marries videogame character. Disponível em:

<http://edition.cnn.com/2009/WORLD/asiapcf/12/16/japan.virtual.wedding/>. Acesso em mai. 2020.
}

Dossiê Feminismos vitais - https://revistaecopos.eco.ufrj.br/

ISSN 2175-8689 - v. 24, n. 1, 2021

DOI: 10.29146/ecopos.v24i1.27538 
ou do convívio diário com vocalóides ${ }^{2}$, hospedadas no espaço doméstico como namoradas e/ou esposas, com quem se troca mensagens de celulares durante o dia, compartilhando ideias sobre o jantar ${ }^{3}$. 0 sucesso da musa pop holográfica Hatsune $\mathrm{Miku}^{4}$, que tem participado de concertos por todo o mundo, reunindo uma legião de fãs, é também um grande exemplo, assim como os pets robôs ${ }^{5}$, que fazem companhia para idosos, crianças e adolescentes e conquistam relações afetivas como aquelas que costumamos ter com animais domésticos como cães e gatos - sendo realizados funerais para os que não têm mais conserto ${ }^{6}$.

Neste artigo, optamos por analisar o exemplo das love dolls, tendo em vista tecer, ao final, alguns caminhos de reflexão que podem conduzir às questões mais amplas referentes aos estudos de gênero, a exemplo das estratégias para lidar com situações de crise e objetificação de pessoas, assim como, da ambígua constituição de laços afetivos, envolvendo os corpos inorgânicos. Autoras como Sibilia (2005) e Braidotti (2013) discutiram a questão do pósorgânico e do pós-humano, assim como os modos como corpos com diferentes materialidades podem construir algum tipo de relacionamento. Historicamente, algumas questões relevantes foram lançadas já nos anos 1980, através do Manifesto Ciborgue (1985) de Donna Haraway e de toda uma produção cinematográfica proposta a partir do lendário filme Blade Runner (1982) de Ridley Scott.

No Japão, as epistemologias do corpo nunca se atrelaram, propriamente, à questão substantiva, ou seja, àquilo que singulariza a res extensa como organismo biológico. Assim, quando a materialidade corpórea se converte em silicone, titânio ou silício, não impacta de maneira significativa a discussão. Como explica Nagatomo (1992), ao analisar as relações entre corpo, mente e ambiente a partir de alguns dos autores japoneses, trata-se, antes de mais nada, do reconhecimento de estados somáticos e do entendimento de um si-mesmo como um estado (provisório e singular) que emerge das conexões e não de identidades prontas e dadas a priori.

\footnotetext{
${ }^{2}$ Vocaloid é um software de sintetização de voz, a partir do qual os usuários podem criar suas próprias músicas. No Japão, foram criados personagens em desenho para associação aos bancos de vozes oferecidos. A estes personagens é atribuído pelos fãs e usuários o termo vocalóide, como forma de identificação dos cantores virtuais. ${ }^{3}$ GATEBOX. Tech. Disponível em: <http://gatebox.ai/tech>. Acesso em mai. 2020.

${ }_{4}^{4}$ Criada em 2007 como personagem para o software Vocaloid, Hatsune Miku é uma cantora virtual que realiza shows holográficos pelo mundo, tendo mais de 2,3 milhões de fãs em sua página de Facebook. Seus fãs possuem papel fundamental em sua construção, sendo eles os autores de suas músicas, videoclipes e figurinos.

${ }^{5}$ AIBO. Disponível em: <https://us.aibo.com/>. Acesso em mai. 2020.

${ }^{6}$ NHK. A funeral for dead robot dogs. Disponível em:

<https://www3.nhk.or.jp/nhkworld/en/news/backstories/346/>. Acesso em mai. 2020.
} 


\section{DOSSIE}

Nunca houve, portanto, um viés essencial ou substancialista para lidar com as noções de sujeito e de organismo. Assim, as concepções de humano no Japão sempre foram múltiplas e fluídas, admitindo-se na vida cotidiana pelo relacionamento com outras materialidades, sejam estes fantasmas, hologramas, bonecas ou personagens digitais. As love dolls fazem parte deste contexto e representam, ao mesmo tempo, uma mercadoria, um objeto sexual, uma companhia, um objeto de desejo e, não raramente, de amor e amizade.

\section{Breve história das bonecas do amor no Japão}

De acordo com Giard (2016), a primeira aparição das love dolls pode ter sido no quinto conto do quinto volume da obra Shokoku koushoku sandai otoko ${ }^{7}$ (諸国好色三代-), escrito por Ihara Saikaku em 1686. O conto trazia a história da jovem moça Komurasaki, que se apaixona pelo funcionário de uma loja administrada por seus pais, chamado Gensuke, que também se apaixona por ela. 0 romance, entretanto, é rapidamente condenado ao fracasso: os dois são forçados a se separar, e os pais de Komurasaki a casam com outro homem escolhido por eles, deixando-a de coração partido. Na noite de núpcias, Gensuke aparece como um fantasma (bakemono, 化け物), em formato de um demônio com chifres, assustando o novo marido. Ao contar do ocorrido para os pais da jovem, eles têm a ideia de produzir uma boneca com a aparência da filha, equipada com a cópia de uma vagina (azuma-gata, 吾妻形) para distrair o fantasma. À noite, o homem, acompanhado da boneca, espera por Gensuke no quarto, que reaparece decidido a matar o rival. Entretanto, ao ver a boneca, Gensuke sente uma atração sexual incontrolável e, tomado por essa paixão, esquece do assassinato e nunca mais retorna. $\mathrm{Na}$ história, a boneca é vista como instrumento de apaziguamento, substituindo o desejo de um homem frustrado e, de forma inédita, é "utilizada explicitamente como parceira sexual” (Giard, 2016, p. 26)

\footnotetext{
7 "O Terceiro homem que só viveu para amar, em todas as províncias", tradução nossa.

${ }^{8}$ No Ocidente, um exemplo de narrativa que traz a relação entre um homem e uma boneca é o conto "O Homem da Areia", de E.T.A. Hoffman, publicado em 1816, no qual o personagem principal, Nathanael, se apaixona por Olímpia, filha do professor e inventor Spallanzani. No decorrer da história, descobre-se que Olímpia é uma boneca autômata, que toca instrumentos, canta e dança. Este conto inspirou muitos artistas, sobretudo a partir do ensaio Das Unheimliche (Inquietante ou Sinistro) de Sigmund Freud, escrito em 1919, no qual analisou a obra de Hoffman.
} 


\section{DOSSIÊ}

Ao traçar a origem das bonecas sexuais, a autora retoma o azuma-gata e as menções a utensílios projetados especificamente para masturbação - cujos primeiros registros datam também de 1686, por meio do livro Koushoku Kinmô Zui (Coleção de imagens eróticas para esclarecer a juventude, tradução nossa), da artista Hanbei Yoshida. Dentre os objetos representados, há o de "uma bainha alargada, provida de uma grande boca ovoide, dividida por uma abertura por cima da qual há algo que parece um capuz de clitóris" (Giard, 2016, p. 41). Junto à imagem, há três caracteres: 吾 (a), que significa eu, a si mesmo; 妻 (tsuma), esposa; e 形 (kata), que diz respeito a forma, formato. A leitura desses caracteres reunidos forma azumagata, que pode ser compreendido como "a forma de minha esposa". Seria, assim, uma ferramenta projetada para homens que dormem sozinhos, como uma espécie de substituto à mulher.

O azuma-gata seria visto, portanto, como o ancestral das bonecas sexuais de hoje. Entende-se ainda que, mais do que um instrumento para a prática sexual, haveria outros valores simbólicos associados à palavra, como a relação a uma situação de exílio ou de um homem sem mulheres - considerando um cenário em que alguns homens, em missões e viagens a trabalho, eram forçados a ficar sozinhos, longe de suas famílias. Em suas palavras:

\footnotetext{
Seguindo um conjunto complexo de alusões ligadas à polissemia da palavra azuma, a expressão azuma-gata refere-se não apenas à ideia de uma sexualidade de compensação, mas à de fidelidade - glorificada pela tristeza - à esposa que o objeto personifica. 0 instrumento que o homem usa para esperar assume o valor de uma promessa. É mais do que uma maneira de obter prazer. É o símbolo de uma distância que desejamos abolir. Esta é a razão pela qual, hoje, a maioria dos japoneses acredita na existência de bonecas azuma-gata como ancestrais das love dolls. Eles cristalizam uma forma de orgulho nacional ligada à noção de amor (Giard, 2016, p. 52, grifos da autora)
}

Tendo em vista o mercado contemporâneo, a Orient Industry (オリエント工業) foi a empresa pioneira na produção das love dolls (ラブドール ou 愛人形), hoje feitas e vendidas por diferentes fabricantes, havendo uma rede de comercialização com oferta de serviços especializados na internet por meio dos blogs e das lojas online, além da exposição em showrooms e em algumas sex shops. Há uma estimativa da Orient Industry de que cerca de duas mil bonecas são vendidas por ano no país.

A primeira boneca lançada pela empresa foi Hohoemi, em 1977. A cabeça e os seios eram feitos de plástico rígido, e o torso e as pernas, de material inflável. Fazia-se necessário, 


\section{DOSSIE}

portanto, enchê-los de ar. A pélvis, para suporte às relações sexuais, era reforçada por um bloco de uretano. Capaz de aguentar o peso de um corpo de até 80 quilos, as principais novidades que a boneca trazia eram a solidez de parte de sua estrutura e a durabilidade, buscando romper com a ideia das bonecas infláveis existentes até o momento, que eram frágeis, deterioravam-se rápido e, de acordo com os usuários, não eram fisicamente atraentes. Hohoemi foi vendida, na época, por 38 mil ienes, de acordo com a Orient Industry em 2017.

A partir de 1982, as bonecas passam a ser produzidas em látex, apresentando como inovação um corpo inteiramente sólido, o que fez o preço subir para 158 mil ienes. Em 1997, são lançadas as Irmãs Hanami (Hanami Shimai, 華三姉妹), uma nova proposta da empresa que explorava uma aparência física mais jovial e colorida, agora apresentadas em três versões: Mika, Yuuka e Ayaka. Feitas de látex e plástico, eram comercializadas por 240 mil ienes. Em 1999, são lançadas love dolls em plástico, oferecendo maior facilidade na limpeza e cuidados e diminuição nos custos de produção, reduzidos então para 168 mil ienes.

No ano de 2001, surge Jewel, a primeira boneca sexual japonesa feita em silicone - já existente no mercado estadunidense desde 1997 com a empresa Abyss Creations e suas real dolls (bonecas reais ou bonecas de verdade, tradução nossa). Após um período de pesquisa e desenvolvimento, ela passou a ser vendida no Japão por 560 mil ienes. Desde então, surgiram novos modelos até chegar ao catálogo atual.

Hoje, as bonecas são vendidas por cerca de 480 a 700 mil ienes, preços que variam de acordo com a personalização selecionada pelo cliente. Há quatro opções base para escolha, que se diferenciam por um determinado padrão de aparência física: Yasuragi, Ange, Jewel e Berry. A partir desta primeira seleção, fica ao critério do comprador decidir sobre o formato do corpo, a cor da pele, o tamanho dos seios, a cor dos mamilos, a cabeça, a possibilidade de movimentar os olhos, a flexibilidade dos dedos e a quantidade de pelos pubianos. A empresa possui um showroom e disponibiliza visitas sob reserva, que duram em média 20 minutos, para que os clientes e as pessoas interessadas possam analisar as bonecas pessoalmente. As encomendas podem ser realizadas pelo site, com entrega no endereço de preferência do comprador, e também pessoalmente no showroom ${ }^{9}$.

${ }_{9}^{9}$ ORIENT INDUSTRY. Disponível em: <https://www.orient-doll.com>. Acesso em mai. 2020. 


\section{DOSSIE}

Além disso, no mercado atual, existem diferentes fabricantes especializadas, como a 4 Woods $^{10}$, a Harumi Designs ${ }^{11}$ e a Level- $D^{12}$; e revendedores de bonecas importadas de outros países, em especial da China. Dentre os materiais mais utilizados para a produção estão o silicone, de consistência mais firme, que costuma elevar o preço dos produtos; e o TPE (Elastômero Termoplástico), opção mais barata e de estrutura mais macia. Pela internet, além das lojas específicas, há também a venda por sites de varejo como Amazon ${ }^{13}$ e AliBaba ${ }^{14}$.

Por parte dos revendedores ou das lojas especializadas, como exemplificado pela Orient Industry, é comum a disposição das love dolls em showrooms, que podem ser visitados geralmente sob agendamento prévio, para que os interessados possam verificar pessoalmente o material, tamanho e qualidade antes de fazer a aquisição. Por conta das dimensões e do peso, elas são vendidas sob encomenda e entregues no local de escolha do cliente. Além disso, os fabricantes possibilitam a personalização das bonecas, sendo disponibilizadas para a escolha das características como altura, cor e formato do corpo, tamanho dos seios, desenho do rosto, cor dos cabelos, quantidade de pelos pubianos e articulação das mãos e pés, por exemplo.

É possível ainda encontrar as bonecas para venda em lojas de artigos sexuais. Durante o período de pesquisa no Japão, visitamos algumas sex shops nos distritos de Akihabara e Ueno, em Tóquio. Em Ueno, encontramos a loja Wildone, de menor porte, e a M's, com cinco andares e diferentes seções. Ambas vendiam apenas bonecas infláveis ou em forma de travesseiro, de produção mais simples e de preço mais baixo. Algumas delas, apesar de possuírem cabeça, não tinham rosto definido, possibilitando a personalização por parte do cliente.

Em Akihabara, conhecemos dois estabelecimentos: Love Merci e Pop Life Department $M$ 's, com quatro e sete andares, respectivamente. 0 primeiro deles não permitia a entrada de mulheres em determinadas seções - segundo as orientações da vendedora, a presença de uma mulher nestes locais poderia inibir ou constranger os clientes homens. Lá estavam dispostos acessórios e instrumentos para masturbação, sendo colocadas à vista poucas unidades de bonecas sexuais, disponíveis para compra sob encomenda. A segunda loja permitia acesso livre

\footnotetext{
10 4WOODS. Disponível em: <https://aidoll.4woods.jp/en/>. Acesso em mai. 2020.

${ }^{11}$ HARUMI DESIGNS. Disponível em: <https://www.harumidesigns.biz/shop >. Acesso em mai. 2020.

12 LEVEL-D. Disponível em: <http://www.level-d.net/>. Acesso em mai. 2020.

13 AMAZON. Disponível em:

< https://www.amazon.co.jp/dp/B08CJZ3YN8/ref=cm sw em r mt dp U qH6gFbNPKNPTP>. Acesso em mai. 2020.

${ }^{14}$ ALIBABA. Disponível em: <https://www.alibaba.com/showroom/sex-love-doll.html>. Acesso em jul. 2020.
} 
em todas as áreas, havendo apenas uma boneca disposta em uma vitrine, além de pôsteres divulgando outras opções da fabricante. De acordo com o vendedor, por conta do tamanho e do peso das bonecas, elas também eram vendidas apenas por encomenda. Além das bonecas de corpo inteiro, as lojas físicas e on-line disponibilizam também opções de partes vendidas separadamente, em geral divididas em: superior (cabeça e busto), inferior (pernas, nádegas e genitália), ou apenas a cabeça ou a genitália. Estas não estariam necessariamente condicionadas ou mesmo relacionadas à montagem de um corpo inteiro, sendo muitas vezes utilizadas separadamente.

Uma característica comum é a constituição das bonecas sexuais japonesas em pelo menos três partes: o corpo, a cabeça e a vagina - sendo a boca não penetrável. Em geral, é possível desencaixar a cabeça e trocá-la por outras opções. Segundo Giard (2016), esse aspecto as diferencia das bonecas produzidas nos Estados Unidos, que eram inicialmente moldadas em uma só peça, sendo possível a penetração pela boca. Com o corpo dividido em pedaços, a love doll é, de certa forma, "dissociada" de si mesma, capaz de virar a cabeça em uma direção e apontar um braço para outra. Essa desarticulação parece ser o ponto essencial das bonecas japonesas, não apenas como aspecto técnico, mas no sentido de que pode variar a forma de se relacionar com elas, sempre em função da vontade e do desejo de quem a manipula. Por conta disto, uma indagação que esteve conosco durante toda a pesquisa foi até que ponto seria possível assumir que esta subserviência ao desejo e vontade do outro seria uma forma de sujeição para replicar as relações de poder entre gêneros na cultura japonesa.

Em visita ao showroom da Orient Industry, pudemos conversar rapidamente com um de seus funcionários para entender sua percepção sobre as love dolls. De acordo com ele, as bonecas poderiam ser vistas como obras de arte, considerando todo seu processo de produção que envolve etapas como o desenho e a moldagem, além do cuidado e do preparo envolvido. Destaca-se ainda que a equipe responsável contempla escultores e maquiadores - muitos formados em faculdades de arte. Sendo tomados os cuidados necessários, como a limpeza, os banhos de talco e as eventuais manutenções e reparos, espera-se que as bonecas possam permanecer por décadas ao lado de seus usuários. Esta característica artística, que implica em um cuidado, tanto da parte dos criadores das bonecas como dos usuários, sugere uma complexidade na relação entre os corpos que não apazigua as relações de poder, mas faz pensar em outras questões, sobretudo voltadas à solidão e à clausura que marcam o Japão 


\section{DOSSIE}

contemporâneo - um fenômeno que, em sua radicalidade, é conhecido com o nome de hikikomori ${ }^{15}$.

Tendo em vista a troca de informações, dicas, relatos e experiências, há no ambiente online diferentes blogs, fóruns, e grupos e páginas em plataformas de mídias sociais como Facebook e Twitter. A partir de alguns depoimentos, é possível verificar usos e significados que extrapolam a esfera sexual. No site Lovedoll Warehouse, revendedor de bonecas chinesas para o público japonês, por exemplo, alguns dos clientes compartilham suas as experiências pessoais e os motivos pelos quais fizeram as aquisições ${ }^{16}$. Dentre eles, há o relato de um senhor que vive com bonecas há mais de vinte anos e as considera parte de sua vida. Morando com três bonecas, ele diz que, mesmo que eventualmente perca o desejo sexual, não consegue imaginar a vida sem elas ${ }^{17}$. Em outro depoimento, uma mulher conta que encontrou na boneca a sua melhor amiga ${ }^{18}$. Ao perceber seu interesse em outros corpos femininos, sentiu que não havia ninguém que a entendesse. Com a boneca, ela declara se sentir confortável para conversar e comenta também tê-la como parceira para a prática sexual. Outros usuários descrevem a importância que elas têm como companhia ou como forma de superar problemas pessoais que em geral envolvem a relação com outras mulheres.

\section{0 adeus às bonecas}

A partir deste cenário, considerando uma quantidade expressiva de depoimentos afetivos em relação às bonecas, a empresa Ningen Love Doll ${ }^{19}$ (人間ラブドール), realizou, no final de 2019, uma pesquisa pela internet com homens e mulheres usuários de love dolls no Japão para entender o mercado e a demanda por um serviço diferenciado de despedida e

\footnotetext{
150 termo hikikomori, como explica o médico e escritor Tamaki (2013), diz respeito às pessoas que vivem enclausuradas em casa, muitas vezes dentro de seus próprios quartos sem se comunicar presencialmente com ninguém. Tudo que fazem - pedir comida, participar de festas, conversar, sexo etc - é através da internet. A este respeito, consultar também Saito e Greiner (2013).

${ }^{16}$ LOVE DOLL WAREHOUSE. Impressions. Disponível em: <https://www.lovedoll-warehouse.net/impressions $>$. Acesso em mai. 2020.

17 LOVE DOLL WAREHOUSE. ラブドールは私の生活の一部です. Disponível em: <https://www.lovedollwarehouse.net/impressions/ashinagaojiisan.html>. Acesso em mai. 2020.

18 LOVE DOLL WAREHOUSE. 私をわかってくれる親友. Disponível em: <https://www.lovedollwarehouse.net/impressions/freeter.html>. Acesso em mai. 2020.

19 "Boneca do amor humana", tradução nossa.

NINGEN LOVE DOLL. Disponível em: <https://ningenlovedoll.com>. Acesso em mai. 2020.
}

Dossiê Feminismos vitais - https://revistaecopos.eco.ufrj.br/

ISSN 2175-8689 - v. 24, n. 1, 2021

DOI: 10.29146/ecopos.v24i1.27538 


\section{DOSSIE}

descarte das bonecas. Dentre os 216 respondentes, $26,8 \%$ afirmaram que gostariam de se despedir por meio de um funeral e $26,4 \%$ disseram que não conseguiam se desfazer por terem apego emocional ou por se importarem com o julgamento de outras pessoas ${ }^{20}$. A partir desses dados, a empresa resolveu começar, em janeiro do ano seguinte, o serviço funerário voltado especialmente para bonecas sexuais, buscando "ajudar no descarte responsável da love doll, uma parceira insubstituível".

As atividades da empresa Ningen Love Doll, representada pela fotógrafa Reiya Arata, começaram, de fato, no final de 2017, oferecendo inicialmente a possibilidade de realizar uma sessão de fotos reversa, na qual os clientes são vestidos, maquiados e tratados como love dolls durante a experiência ${ }^{21}$. Há diferentes pacotes, cujos preços vão de 50 mil a 120 mil ienes, que variam de acordo com os produtos inclusos (livro de fotos, revelação em acrílico, maquiagem, tratamento dos seios e possibilidade de fotografar em um estúdio ou local de preferência, por exemplo). De acordo com o site da empresa, o estúdio seria um local para "esquecer de si mesmo por um momento". Ao entrar na sala, o cliente se torna uma boneca e, portanto, a partir de então, não pode mais falar ou se movimentar de forma autônoma - sendo posicionado a partir das orientações da fotógrafa.

No início de 2020, após a conclusão da pesquisa de mercado, a empresa passa a oferecer também o serviço funerário para bonecas sexuais. Idealizado por Reiya Arata, entusiasta do universo e participante ativa de uma rede on-line de proprietários de love dolls, a ideia surgiu não só pela possibilidade de uma despedida íntima, mas também como forma de facilitar o descarte, dificultado por diversos motivos, como as normas japonesas de descarte de lixo que restringem tamanho, material e forma como devem ser jogados, que variam de acordo com a localidade - sendo necessário, muitas vezes, pagar pelo descarte de objetos maiores, por exemplo. Outro obstáculo é o formato da boneca, que muitas vezes acaba sendo confundida com um cadáver abandonado ou esquartejado, causando desconforto entre os vizinhos. No serviço oferecido pela empresa, o descarte está incluso no pacote: após o funeral, as bonecas são encaminhadas para uma empresa parceira de tratamento de lixo industrial, responsável pela cremação dos corpos.

\footnotetext{
${ }^{20}$ Press release Ningen Love Doll. Disponível em: $<$ https://www.value-press.com/pressrelease/234875>. Acesso em mai. 2020.

${ }^{21}$ NINGEN LOVE DOLL. Disponível em: <https://ningenlovedoll.com/>. Acesso em mai. 2020.
} 


\section{DOSSIE}

Algumas empresas japonesas, como a Orient Industry, oferecem a possibilidade de retornar a boneca para o descarte. No Japão, há cerimônias religiosas da despedida e do agradecimento para bonecas e brinquedos. Os funerais para bonecas, em japonês, ningyo kuyo (人形供養) ${ }^{22}$ são uma oportunidade para agradecer o tempo de companhia, purificá-las e se despedir - ao final, elas são queimadas. As bonecas que retornam à Orient Industry, por conta do tamanho, não podem ser levadas inteiras. São cortadas, então, mechas de cabelo ou selecionados pequenos itens que representem a boneca para levar às cerimônias. Apesar dessa possibilidade ser oferecida por algumas empresas, é importante considerar que muitas são importadas de fabricantes chinesas, que não dispõem da opção de envio.

Na Ningen Love Doll, a cerimônia fúnebre é realizada por Rei Kato, monja budista e atriz de filmes pornográficos. Há, atualmente, três opções de planos, que vão de 30 mil a 90 mil ienes. 0 mais barato é um plano conjunto, no qual o memorial é dedicado a várias bonecas de uma única vez, destinado aos que não querem gastar muito e têm interesse em realizar um funeral em grupo. Por 30 mil ienes, estão inclusos o memorial em grupo, o funeral, um certificado e uma foto (também coletiva), além do descarte. A opção intermediária, no valor de 50 mil ienes, contempla um funeral realizado especialmente para a boneca de cada cliente, possibilitando uma despedida mais personalizada e próxima, incluindo memorial e funeral individuais, emissão de certificado, filme ou foto, a leitura de uma carta dedicada à boneca e a participação do cliente por meio de videoconferência. 0 plano mais caro, de 90 mil ienes, chamado "Plano Anjo", oferece, além dos serviços mencionados nos demais pacotes, a possibilidade de participação do cliente de forma presencial ou por videoconferência, sendo outro diferencial a opção de que, como parte do ritual, a boneca seja desmantelada por cortes de espada, ao invés de diretamente destruída pela empresa responsável pelo descarte. Além disso, é possível guardar uma das partes de seu corpo como lembrança ${ }^{23}$.

Como opcionais, há a possibilidade de uma última foto feita no caixão (dependendo da condição da boneca) por 5 mil ienes; de um descarte exclusivo da boneca por parte da empresa responsável, não misturando-a com outras coisas por 50 mil ienes; e um vídeo do memorial por 5 mil ienes - para os pacotes nos quais este serviço não está incluso.

22 NINGYO KUYO. Disponível em: <http://www.ningyo-kuyo.com/index.html>. Acesso em mai. 2020.

${ }^{23}$ NINGEN LOVE DOLL. ドール葬儀社. Disponível em : <https://ningenlovedoll.com/doll>. Acesso em jul. 2020.

Dossiê Feminismos vitais - https://revistaecopos.eco.ufrj.br/

ISSN 2175-8689 - v. 24, n. 1, 2021

DOI: 10.29146/ecopos.v24i1.27538 


\section{DOSSIE}

Para uso do serviço, os interessados devem fazer as solicitações por e-mail, pagar as taxas funerárias por transferência bancária ou cartão de crédito, e enviar a boneca para a sede da empresa, localizada em Osaka. O cliente é notificado da chegada ao local de destino e os responsáveis se encarregam de fazer companhia à boneca até a data do funeral. A cerimônia é realizada de acordo com o plano escolhido e o corpo enviado para a empresa parceira responsável pelo descarte. Por fim, são enviados os certificados, fotos e vídeos por e-mail - e, no caso do "Plano Anjo", também as partes da boneca a serem guardadas como lembrança.

Durante a pesquisa de campo no Japão, entrevistamos a idealizadora da empresa, Reiya Arata em seu estúdio na cidade de Yashio, província de Saitama. Arata explicou que o interesse pelas bonecas começou quando ouviu falar de uma empresa em Osaka que oferecia o serviço de locação de bonecas sexuais e resolveu pesquisar mais sobre elas, encantando-se pelo estilo e, sobretudo, pela maquiagem. Há pouco mais de dois anos, passou a se perguntar como essa estética poderia ser aplicada às pessoas e decidiu começar com as sessões de fotos temáticas.

Ao ser questionada sobre como a sociedade japonesa vê os usuários de love dolls, Arata relatou que, de um modo geral, a relação com bonecas ainda é vista como tabu por muitas pessoas. Em relação à visão das bonecas em outros países, ela menciona a repercussão da produção de modelos em formato infantilizado, muito polemizada e considerada crime em algumas localidades. Ela destaca, entretanto, que há diferentes formas de relação com a boneca não necessariamente sexuais, incluindo, por exemplo, o carinho paternal ou maternal. Ela contou sobre a sua própria experiência, como alguém que possui duas bonecas (uma delas em tamanho infantil), e que nunca praticou atos sexuais com a "boneca-menina". Especificamente em seu caso, ela afirma vê-las como animais de estimação, com um propósito de companhia. Em sua percepção, haveria uma diferença grande entre a visão do público geral e a dos usuários em torno das relações com as love dolls, bem como a influência de aspectos culturais nessas relações. Na China, por exemplo, as bonecas, com custo mais baixo e deterioração mais rápida, são jogadas fora com mais facilidade. No Japão, elas, em especial as feitas de silicone, são vendidas a preços mais elevados e, tomando os cuidados necessários, podem durar mais de dez anos. Em relação à aparência, ela destaca que apesar de existirem diferentes tipos de 


\section{DOSSIE}

rostos, a estética kawaii ${ }^{24}$ está sempre muito presente no contexto midiático e de consumo no Japão. ${ }^{25}$

Arata destaca também casos de pessoas que têm dificuldades ou falta de interesse em conversar e se relacionar com outras pessoas, como acontece com os hikikomori, devido à opção por viver em reclusão. Nestes casos, as bonecas são uma forma de driblar a solidão. Há também situações em que se "compensa" a falta de uma filha falecida ou a perda de outro ente querido. As bonecas seriam, nesse sentido, também importantes ferramentas de conforto ou suporte aos usuários. Por conta desse apego, muitos têm dificuldade em descartá-las. Arata menciona que alguns donos mais velhos, apesar de não quererem jogá-las fora, têm de abrir mão delas em algum momento por conta das próprias limitações de saúde, sendo muitas vezes necessário o acompanhamento de profissionais em suas rotinas diárias ou a transferência para instituições de cuidado - dificultando ou impossibilitando a manutenção das bonecas - que além de demandarem alguns cuidados, são também difíceis de locomover por conta do peso, que pode chegar a mais de 40 quilos.

Ao mostrar uma de suas bonecas, doada por um antigo dono que a jogaria fora, ela aponta algumas partes que vieram danificadas quando a recebeu: um dos braços estava esburacado e a cabeça tinha um pequeno corte na parte inferior. Comprada originalmente há três anos pelo site Amazon por cerca de 30 mil ienes, a boneca acabou não recebendo alguns cuidados necessários (como banho ou o uso de talco), pois o usuário não conhecia o modo de uso e manutenção. Ao recebê-la já desta forma e pensando nas novas limitações que estariam por vir, Arata chegou à conclusão de que gostaria de dar à boneca uma cerimônia de despedida. Por isso, procurou a respeito dos funerais e das formas de descarte e viu que as empresas de lixo, apesar de aceitarem o material, deixavam-nas em uma situação visualmente desagradável, deixando alguns usuários desconfortáveis em se despedir dessa forma. Foi quando teve a ideia de começar a realizar os funerais para que as pessoas pudessem criar boas memórias antes de se despedir.

\footnotetext{
24 "Adorável ou fofo", tradução nossa.

25 De acordo com Kinsella (1995), o termo kawaii é caracterizado por um comportamento social específico e aparência física doce, inocente, genuíno, vulnerável e inexperiente. Em outros países, entretanto, esse aspecto parece ser desvalorizado ou associado a uma atitude infantilizada.
} 


\section{DOSSIE}

No tópico a seguir, apontamos caminhos para análise a partir de autores que partem de uma lógica não-dicotômica e sugerem novas perspectivas para o contexto de crise em que vivemos, estando este em processo constante de ressignificação.

\section{Um outro olhar para o corpo e seus afetos}

As love dolls têm suscitado vários questionamentos. 0 primeiro deles diz respeito às lógicas dualistas que, muitas vezes, parecem nortear essas discussões. Ao colocar em evidência o relacionamento entre os usuários e as suas bonecas, parece importante lidar com uma epistemologia que não parte exclusivamente do pensamento moderno Ocidental, do qual emergiram uma série de dicotomias como: corpo/mente, natureza/cultura, sujeito/objeto, orgânico/inorgânico e pessoa/coisa.

Há, evidentemente, autores no Ocidente que já problematizaram esta lógica dual, que ainda guarda vestígios do pensamento cartesiano. Esposito (2016), por exemplo, tem buscado identificar de que forma a organização da experiência humana foi construída a partir da divisão reducionista e excludente entre pessoas e coisas, no entendimento que, de tão enraizado no senso comum, passa por nós de forma natural, sem considerarmos, entretanto, essa dicotomia como fruto de um extenso "processo de disciplinamento que percorreu a história antiga e moderna justificando seus contornos" (Esposito, 2016, p. 1).

0 autor explica como essa categorização se instituiu desde a constituição do direito romano até os dias atuais e da maneira com que, a partir dessas definições, são construídas as relações da posse e do domínio - sendo, a princípio, a pessoa quem possui e exerce domínio sobre as coisas. Entre a coisa e a pessoa "dá-se uma relação de domínio instrumental, no sentido de que o papel das coisas é o de servir, ou pelo menos de pertencer, às pessoas" (Esposito, 2016, p. 16).

0 aspecto político que norteia essa discussão indaga quem pode ser definido como pessoa e quem não pode, assim como quem seria considerado pessoa só a partir de determinadas condições. Segundo o autor, é como se houvesse graus de humanidade, o que abre um precedente para "excluir algumas tipologias humanas dos benefícios concedidos a outras, para fazer delas pessoas-coisas a serem usadas e destruídas" (Esposito, 2016, p. 28), a 
exemplo da escravidão que assolou a história em diferentes períodos e que, mesmo tendo sido formalmente abolida, continua nos assombrando de muitas formas até os dias atuais.

Esposito (2016) afirma, ainda, que estudos antropológicos apresentam sociedades nas quais:

Pessoas e coisas fazem parte do mesmo horizonte, a ponto de não somente interagirem, mas de se integrarem mutuamente... Nesses casos, mais do que meros instrumentos ou objetos de propriedade exclusiva, as coisas constituem o filtro mediante o qual os homens, ainda não modelados pelo dispositivo da pessoa, entram em relação entre si (Esposito 2016, p. 2).

Neste sentido, completa:

Quanto mais os objetos técnicos incorporam, com o saber que os tornou fungíveis, uma espécie de vida subjetiva, tanto menor é a possibilidade de sufocá-los em uma função exclusivamente servil. Ao mesmo tempo, por meio do uso das biotecnologias, as que um tempo pareciam mônadas individuais, podem incluir dentro de si elementos oriundos de outros corpos e até de materiais inorgânicos. Dessa forma, o corpo humano passa a ser o canal de trânsito e o operador, sem dúvida muito delicado, de uma relação sempre menos redutível a uma lógica binária (Esposito, 2016, p. 3)

Por sua vez, Perniola (2005) observa a diferenciação entre o ser vivo como algo que sente, enquanto o ser inanimado, não teria tal habilidade. Buscando fugir de uma visão antropocêntrica, que toma o homem como parâmetro soberano do mundo, o autor discute novas formas do sentir, partindo do encontro entre filosofia e sexualidade para entender diferentes manifestações no contexto contemporâneo. Em suas palavras, nesse contexto:

A transformação do sujeito numa coisa que sente parece fazer parte de um imaginário de ficção científica em que o orgânico e o inorgânico, o antropológico e o tecnológico, o natural e o artificial se sobrepõem e se confundem um com o outro. De fato, a partir do momento em que a ficção científica introduziu, entre o homem e o robô, figuras intermediárias que apresentam aspectos tanto de um quanto de outro, abriu-se uma vasta problemática a qual remete à natureza de um sentir que ainda não é plenamente humano (como no caso do replicante, do androide e do simulacro), ou que não é mais humano (como no caso do cyborg, isto é, de um homem em cujo corpo foram introduzidas várias próteses). Contudo, a orientação geral de tal imaginário permanece mais humanista e naturalista: não obstante essas formas intermediárias serem até superiores ao homem nas específicas prestações funcionais em vista das quais foram produzidas, de um ponto de vista global, elas permanecem inferiores ao seu inventor e criador. Esta dependência do modelo humano caracteriza não só o replicante, cuja diferença em relação ao original, embora não visível, permanece relevante, mas também

Dossiê Feminismos vitais - https://revistaecopos.eco.ufrj.br/

ISSN 2175-8689 - v. 24, n. 1, 2021

DOI: 10.29146/ecopos.v24i1.27538 


\section{DOSSIE}

o cyborg, que não consegue ser nada além de um homem potencializado e aperfeiçoado (Perniola, 2005, p. 45-46).

Assim, estaríamos inseridos em um universo poroso e a experiência contemporânea seria marcada por uma convergência e, por vezes, até por uma indistinção entre o ser humano e a coisa.

Na cultura japonesa, a questão se coloca de forma distinta. Não se trata de buscar convergências ou de desestabilizar hierarquias entre o vivo e o não vivo. Há uma lógica de ambivalência que emerge desde o início e que não implica em escolher entre um e outro, mas sim, em reconhecer que coisa e pessoa se constituem em processo co-evolutivo. Uma das fontes mais antigas desse debate está no chamado animismo, que admitiria a presença da alma ou anima em seres animados e inanimados. Outra matriz importante para esses debates seria o teatro de bonecos no Japão. Na cena deste gênero teatral, há uma continuidade entre o corpo do manipulador e o corpo do boneco, de modo que se torna irrelevante reconhecer onde termina e onde começa o corpo de um e de outro (Souza, 2005). A subjetividade, de fato, se constitui na relação.

0 mesmo se passa quando o tema é a tecnologia e nossas habilidades cognitivas. Assim como já observaram autores como Clark (2012), a memória não está no cérebro ou na conexão corpo-cérebro, mas também na conexão corpo-cérebro-dispositivo tecnológico. A memória emerge das relações. Nesta perspectiva, o smartphone, o computador ou os antigos cadernos de telefone não são suportes para memória. É a própria memória humana que se constitui nestas relações, em rede.

Na cultura japonesa, a indistinção entre animado e inanimado e a possibilidade de amar personagens, fantasmas, bonecas e robôs também é admitida há séculos, como visto a partir da pesquisa de Giard (2016). Neste sentido, pode-se admitir que o afeto é constituído na relação e em rede, como a memória pesquisada por Clark (2012). Por isso, não é exclusivo do corpo animado ou do inanimado, mas sim, algo que se constitui na relação. A materialidade dos corpos não seria, nesse viés, nem exclusivamente biológica, nem cultural, mas composta pelos fluxos sígnicos.

No entanto, destaca-se que essas alianças e esses atravessamentos entre os corpos não garantem a inexistência das relações de poder. A própria Giard (2016) tem indagado a razão 


\section{DOSSIE}

pela qual as bonecas são, em grande maioria, representações de mulheres. Apesar de existirem versões masculinas, a gama de opções e de possibilidades de personalização são incomparavelmente menores se comparadas à oferta de bonecas femininas.

Ao conversar com alguns criadores de bonecas, a autora destaca a fala do presidente da Orient Industry, de que elas seriam um instrumento para aperfeiçoar uma simulação e que seriam reservadas exclusivamente ao público masculino, pois não podem se mover. Essa afirmação partiria da convicção de que, numa relação, o homem seria a parte ativa e, assim, a mulher deveria "sofrer, oferecer-se, abrir-se, submeter-se e esperar" (Giard, 2016, p. 238). Por mais preconceituosa e ficcional que seja a justificativa, ela toma como base um padrão patriarcal de relacionamento homem-mulher que ainda parece vigente, apesar de todas as conquistas do feminismo japonês.

Como a materialidade do corpo é sígnica (uma natureza eminentemente cultural), para lidar com a alteridade é insuficiente compreender apenas como funciona a nossa percepção do ponto de vista orgânico. Lidar com o outro - como pontua Butler (2003), entre outros autores implica em uma ação performativa que, por sua vez, aciona relações de poder. A indistinção entre corpo inanimado e corpo animado no Japão se alinha, de certa forma, a esses modos não substantivos de pensar os corpos. Isto não significa que as relações de poder são neutralizadas no mercado de trabalho, nas relações afetivas e no que diz respeito às sexualidades. No entanto, pode-se considerar que o reconhecimento da fluidez sígnica, tanto dos corpos animados como dos inanimados, complexifica a discussão, sobretudo, ao problematizar as hierarquias (entre pessoa e objeto) e os juízos de valor.

\section{Considerações finais}

Neste artigo, buscamos apresentar o estado da arte do mercado de bonecas sexuais japonesas e as formas de relação que emergem deste contexto. Observamos como o uso das bonecas extrapola o âmbito sexual, acionando laços afetivos que resultaram no surgimento, por exemplo, de serviços de funeral para bonecas sexuais. 


\section{DOSSIE}

Há empresas especializadas em bonecas sexuais em diversos países, como o Reino Unido, a China, os Estados Unidos e a Espanha, com exportação em escala mundial. Na China ${ }^{26}$, Estados Unidos ${ }^{27}$ e Espanha ${ }^{28}$ têm sido desenvolvidos, inclusive, robôs sexuais equipados com inteligência artificial, movimentos corporais e mudança de temperatura corporal de acordo com a realização da prática sexual. Em contraponto, surgem também movimentos contra o desenvolvimento de tais tecnologias, como é o caso da Campanha Contra Robôs Sexuais, liderada por Kathleen Richardson, professora na Universidade de Montfort, na Inglaterra. No site oficial do movimento, Richardson afirma que tais iniciativas agravam a tendência à objetificação das mulheres - considerando que a maior parte das bonecas e robôs representam um corpo feminino, e dessa forma acentuam a desigualdade e a violência de gênero ${ }^{29}$.

A indústria de bonecas fortalece, por um lado, as questões já amplamente discutidas em debates de gênero e direitos humanos, a partir do momento em que de fato mercantiliza o corpo feminino. No entanto, ao mesmo tempo, a partir da pesquisa realizada, não podemos deixar de destacar os laços afetivos e as diferentes formas de relação entre os usuários e as suas bonecas, decorrentes, em parte, da alta taxa de solidão, devido às consequências da reclusão e da exclusão social. No Japão, a reclusão não começou recentemente, nem está diretamente relacionada ao risco da contaminação com Covid-19, mas já faz parte da cultura há muitas décadas, recebendo o nome de hikikomori.

A partir da necessidade de isolamento social decorrente da pandemia, as pessoas viramse forçadas a restringir ainda mais o contato umas com as outras, sendo encontradas, assim, novas maneiras de se relacionar, em boa parte por meio da tecnologia - com videoconferências e transmissões ao vivo para conversas, palestras, shows, ou mesmo festas de aniversário. Neste cenário, que radicalizou as situações de solidão, a procura pelas bonecas sexuais cresceu de maneira significativa, não só no contexto japonês. Nos Estados Unidos e no Reino Unido, durante o período de quarentena, as vendas de bonecas sexuais apresentaram crescimento expressivo. De acordo com matéria divulgada pela Forbes em maio de 2020, a loja americana

\footnotetext{
${ }^{26}$ SHENZEN ALL INTELLIGENT TECHNOLOGY. Disponível em: <http://www.ai-aitech.com/>. Acesso em jul. 2020.

27 REAL DOLL. Disponível em: <https://www.realdoll.com/realdoll-x>. Acesso em jul. 2020.

${ }^{28}$ FORBES. How robots, IoT and Artificial Intelligence are changing how humans have sex. Disponível em: $<$ https://www.forbes.com/sites/bernardmarr/2019/04/01/how-robots-iot-and-artificial-intelligence-arechanging-how-humans-have-sex/\#33bc9ad329c3>. Acesso em jul. 2020.

${ }^{29}$ CAMPAIGN AGAINST SEX ROBOTS. Disponível em: <https://campaignagainstsexrobots.org/>. Acesso em jul. 2020.
} 


\section{DOSSIE}

Sex Doll Genie, por exemplo, relatou um aumento de 51,6\% nos pedidos realizados entre os meses de fevereiro e março ${ }^{30}$.

De maneira indireta, tal fenômeno comercial (e existencial) também se relaciona a uma crise que vem se agravando nas últimas décadas e que se refere ao tema da identidade. Os debates de gênero (e especialmente relativos aos transgêneros) têm formulado - inicialmente a partir dos ensaios de Judith Butler publicados no decorrer da década de 1990 e, mais recentemente, através das publicações de Preciado (2014) - a necessidade de se escapar do determinismo biológico e da soberania da lógica dual (homem ou mulher). Além da dicotomia homem e mulher, estes debates desestabilizam o binarismo entre natureza e cultura, na medida em que propõem o reconhecimento do gênero como um processo de constituição que alia natureza e cultura, sem evocar a lógica do um ou outro. Neste sentido, os estudos instaurados pelos atravessamentos entre animado e inanimado no Japão pode colaborar como uma possível epistemologia do corpo que, como mencionamos anteriormente, não parte dos dualismos engendrados pela lógica cartesiana, radicalizando os atravessamentos.

Com o advento das novas tecnologias, muitos autores passaram a discutir, com particular interesse, o dualismo entre sujeito e objeto, muitas vezes mobilizados por questões políticas. Esposito (2016) e Perniola (2005) observaram que os critérios para discutir o que caracteriza uma pessoa (ou um sujeito) variam não apenas no que se refere à constituição do organismo humano, mas na instância política que vigora para garantir o estatuto de pessoa. Pesquisadores como Agamben (2007), Mbembe (2018) e tantos outros têm fortalecido a hipótese de que a perspectiva política é fundamental para assegurar ou para negligenciar o estatuto de pessoa.

Agamben (2007) explica como o homo sacer do Direito Romano, que representava uma vida matável e insacrificável, não existe mais nos textos constitucionais, mas segue presente nas periferias das grandes cidades, nas zonas de guerra e grandes conflitos e em todos os ambientes marcados pelo extrativismo das subjetividades. Mbembe (2018), por sua vez, ao discutir a escravidão e a plantation, que seriam as territorialidades do que tem chamado de

${ }^{30}$ FORBES. Sex Doll Sales Surge In Quarantine, But It's Not Just About Loneliness. Disponível em: <https://www.forbes.com/sites/frankicookney/2020/05/21/sex-doll-sales-surge-in-quarantine-but-its-not-justabout-loneliness/\#e95069a170fb >. Acesso em jul. 2020. 


\section{DOSSIE}

necropolítica, observa como nestas circunstâncias pessoas são convertidas em objetos, mercadorias e moedas.

Todas essas discussões podem ser relacionadas às love dolls criando zonas de ambivalência nem sempre fáceis de serem analisadas. Por um lado, a objetificação feminina e a presença do corpo feminino aos pedaços são índices da soberania masculina no contexto japonês. Ao mesmo tempo, as bonecas do amor são verdadeiras próteses para solidão. Além disso, o serviço fotográfico que simula a maquiagem das bonecas em pessoas cria uma espécie de personificação às avessas que abre novas inquietações. 0 que faz o corpo-pessoa se metamorfosear em corpo-boneca para ser manipulado e deslocado pelo outro?

São, portanto, crises sucessivas de constituição de subjetividades que se escancaram ao estudarmos as love dolls japonesas. Novas versões do animismo tradicional parecem retornar e ressignificar, como propõem Yoneyama (2019) e Mbembe (2020). Ao invés de reconhecer a alma (anima) nos objetos inanimados e nutrir o culto aos ancestrais, segundo Mbembe (2020), alguns dispositivos de poder fazem do animismo uma nova forma de espetacularização e brutalismo, voltada para o culto de si e dos objetos como duplos dos sujeitos. Estas transições, alinhadas às questões relativas aos debates do antropoceno e das urgências ecológicas, tornam os relacionamentos afetivos entre pessoas e bonecas um tema que transborda o mero exotismo, para se tornar um campo de pesquisas que, uma vez descolado dos pressupostos da moralidade cristã, abre questões muito significativas para os debates de gênero, as epistemologias do corpo e dos sujeitos, e as discussões que oscilam entre as políticas para a morte e as políticas para a vida.

\section{Referências bibliográficas}

AGAMBEN, Giorgio. Homo sacer, o poder soberano e a vida nua. Belo Horizonte: UFMG, 2007.

BRAIDOTTI, Rosi. The Posthuman. Cambridge: Polity Press, 2013.

BUTLER, Judith. Problemas de gênero: feminismo e subversão da identidade. São Paulo: Civilização Brasileira, 2003.

ESPOSITO, Roberto. As pessoas e as coisas. São Paulo: Rafael Copetti Editor, 2016.

GIARD, Agnés. Un désir d'humain: les love doll au Japon. Paris: Las belles lettres, 2016.

Dossiê Feminismos vitais - https://revistaecopos.eco.ufrj.br/

ISSN 2175-8689-v. 24, n. 1, 2021

DOI: 10.29146/ecopos.v24i1.27538 
KINSELLA, Sharon. Cuties in Japan. In: MOERAN, Brian; SCOV, Lise. (Org.). Women, Media and Consumption in Japan. London: Curzon \& Hawaii University Press, 1995. p. 220-254.

MBEMBE, Achille. Crítica da Razão Negra. São Paulo: n-1 edições, 2018.

. Brutalisme. Paris: La Découverte: 2020.

NAGATOMO, Shigenori. Attunement through the body. New York: Suny University Press, 1992.

ORIENT INDUSTRY. 愛人形LoveDoll の軌跡〜オリエント工業40周年記念書籍. Tóquio: Micro Magazine, 2017.

PERNIOLA, Mario. O sex appeal do inorgânico. São Paulo: Studio Nobel, 2005.

PRECIADO, Beatriz. Manifesto contrassexual: práticas subversivas de identidade sexual. São Paulo: n-1 edições, 2014.

SAITO, Cecilia.; GREINER, Christine. Hikikomori, a vida enclausurada nas redes. São Paulo: Intermeios 2013.

SIBILIA, Paula. $O$ Homem pós-orgânico: a alquimia dos corpos e das almas à luz das tecnologias digitais. Rio de Janeiro: Contraponto, 2005.

SOUZA, Marco. O Kuruma Ningyo e o corpo no teatro de animação japonês. São Paulo: Annablume, 2005.

TAMAKI, Saitō. Hikikomori: Adolescence Without End. Minneapolis: Minnesota University Press, 2013.

YONEYAMA, Shoko. Animism in Contemporary Japan, Voices for the Anthropocene from Post-Fukushima Japan. Nova Iorque: Routledge, 2019.

\section{Sites consultados}

EROERO. Disponível em: <http://www.ero104.com/flow.html>. Acesso em mai. 2020.

JAPAN TIMES. From sex toys to works of art: 'Love doll' maker seeks to shed seedy image. Disponível em: <https://www.japantimes.co.jp/news/2017/07/05/business/sex-toys-works-art-love-doll-makerseeks-shed-seedy-image/\#.XrsTlmhKjD6>. Acesso em mai. 2020.

LOVE DOLL WAREHOUSE. Impressions. Disponível em: < warehouse.net/impressions/ >. Acesso em mai. 2020.

LOVE DOLL WAREHOUSE. 私をわかってくれる親友. Disponível em: < https://www.lovedollwarehouse.net/impressions/freeter.html>. Acesso em mai. 2020.

LOVE DOLL WAREHOUSE. ラブドールは私の生活の一部です. Disponível em: <https://www.lovedollwarehouse.net/impressions/ashinagaojiisan.html>. Acesso em mai. 2020.

LUMIDOLLS. Disponível em: <https://lumidolls.com/en/>. Acesso em mai. 2020. 


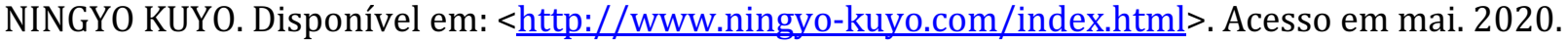

ORIENT INDUSTRY. Showroom. Disponível em: <https://www.orient-doll.com/company/showroom/>. Acesso em mai. 2020. 